\title{
The big-hearted man now in trouble
}

Irma van de Werke
FRCR
Zarina Lockhat
FFRad(D)SA
Betsie van der Walt
FCRad(D)SA
Rowaida Abdullah
MB ChB
Department of Radiology
University of Pretoria

A 74-year-old man with a productive cough was referred from a peripheral hospital. The referral diagnosis queried a calcified echinococcus cyst in the left hemithorax.

\section{Chest X-ray}

Figs 1 and 2 show PA and lateral views. What are the relevant findings? The patient was then referred for an echocardiogram (Figs 3 and 4) and MRI study (Figs 5 - 8). What is your diagnosis?

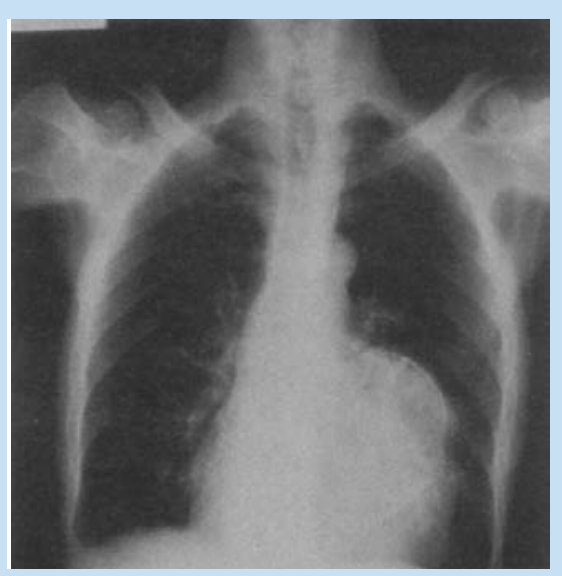

Fig. 1.

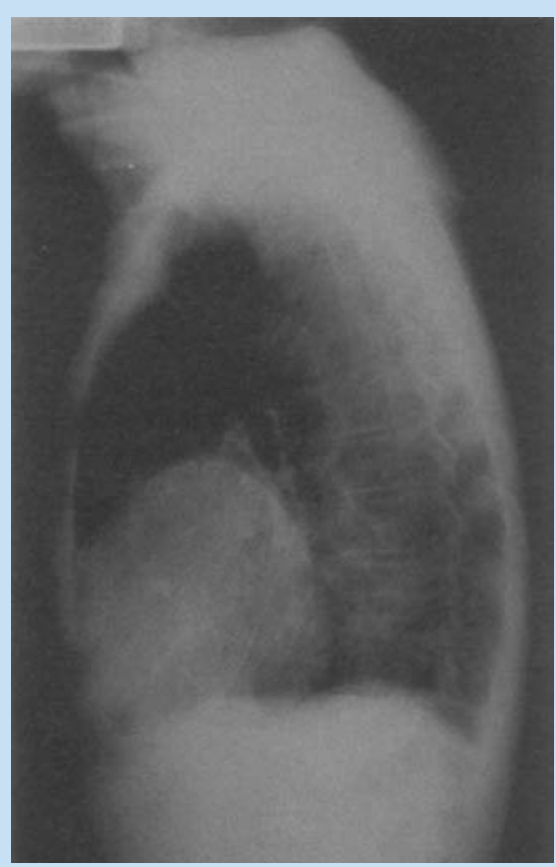

Fig. 2.

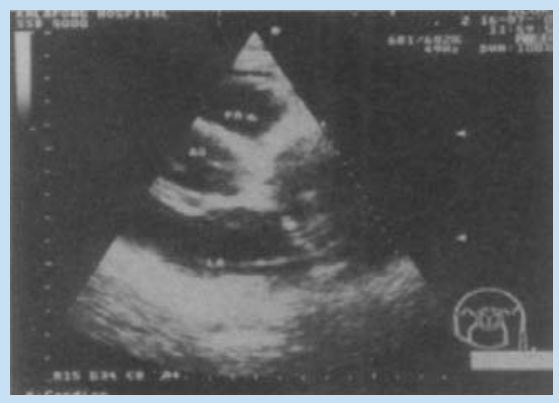

Fig. 3.

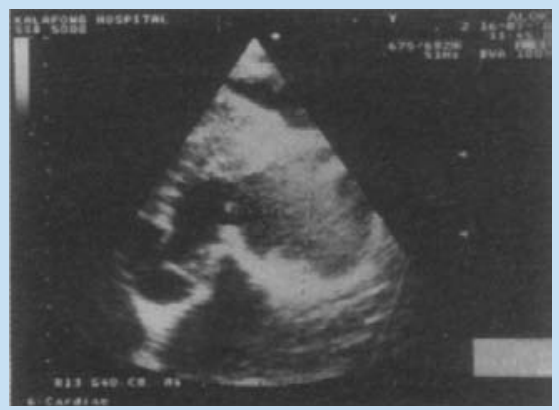

Fig. 4.

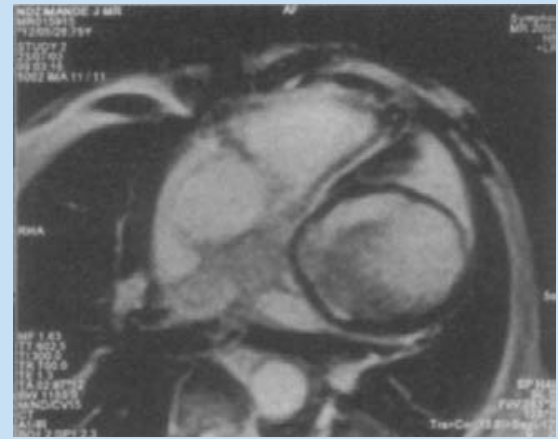

Fig. 5.

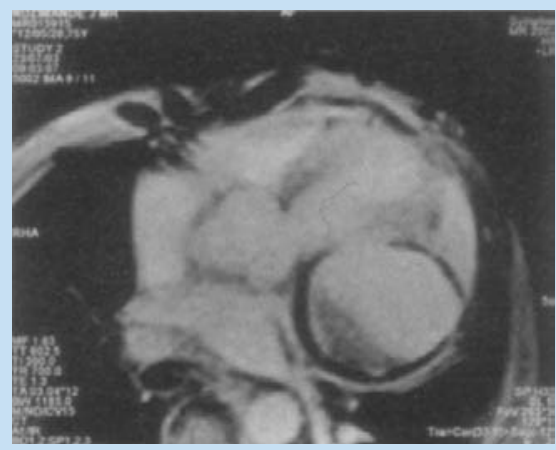

Fig. 6.

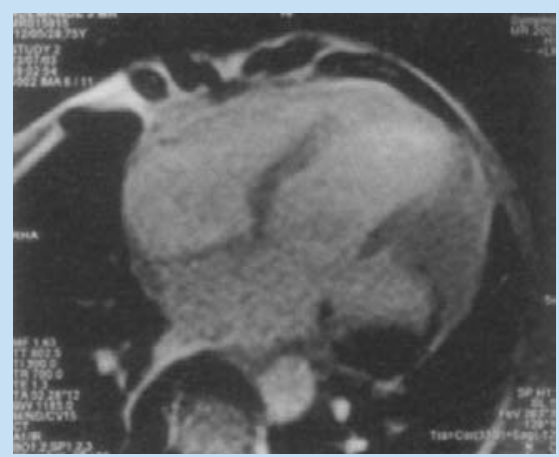

Fig. 7.

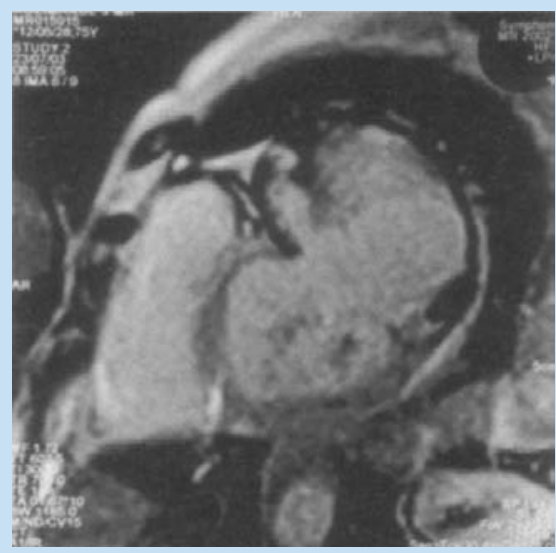

Fig. 8. 


\section{Discussion}

PA and lateral chest X-rays demonstrate cardiomegaly with an ovalshaped mass with rim calcification in the region of the left atrium and ventricle.

\section{Echocardiogram}

A large aneurysm is noted in the region of the left ventricle, at the submitral valve level.

\section{MRI}

The four chamber view shows a large aneurysm in the postero-lateral wall of the left ventricle. It is situated just inferior to the posterior mitral valve cusp. Rim calcification is present. On the two chamber view the aneurysm is again noted in the left ventricular region.

\section{Discussion}

Mitral subannular left ventricular aneurysms are not seen frequently. Those described have occurred mostly in Africa and India. ${ }^{4}$

These aneurysms arise in the fibrous ring below the mitral or aortic valve. The submitral type is more common than the subaortic type. Submitral aneurysms occur in the epicardium, related to the base of the left ventricle.

These aneurysms have ovoid ostia which are frequently multiple and located under the posterior leaflet of the mitral valve.

The aetiology is unknown though a congenital defect in the posterior mitral valve annulus has been postulated.

These aneurysms are false and may reach enormous proportions. They may calcify or contain mural throm- bus. Complications include myocardial ischaemia and infarction, systemic embolisation, congestive cardiac failure and infective endocarditis as well as rupture of the aneurysm. Surgical resection of the aneurysm with or without valve replacement is indicated in severe valvular regurgitation or cardiac failure resistant to medical therapy.

The acquired causes may be due to infection, myocardial infarction, collagen vascular disease, Takayasu's arteritis, myocarditis or trauma.

\section{Addendum}

We refer to the publication of our first case in the South African Journal of Radiology of March 2002. ${ }^{6}$ The subsequent case demonstrates the different plain chest film and ultrasound appearances of the subannular left ventricular aneurysms (Figs 9 - 12).

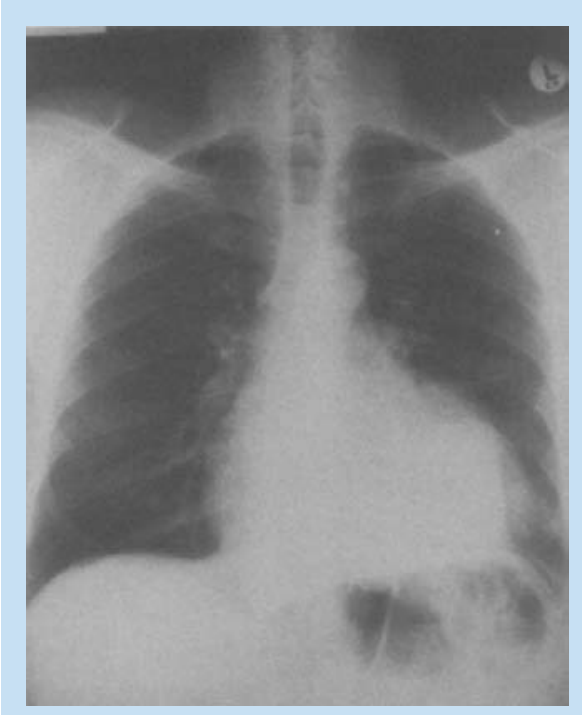

Fig. 9.

\section{Acknowledgement}

We would like to thank Annelize Gates for her assistance in preparation of this article.

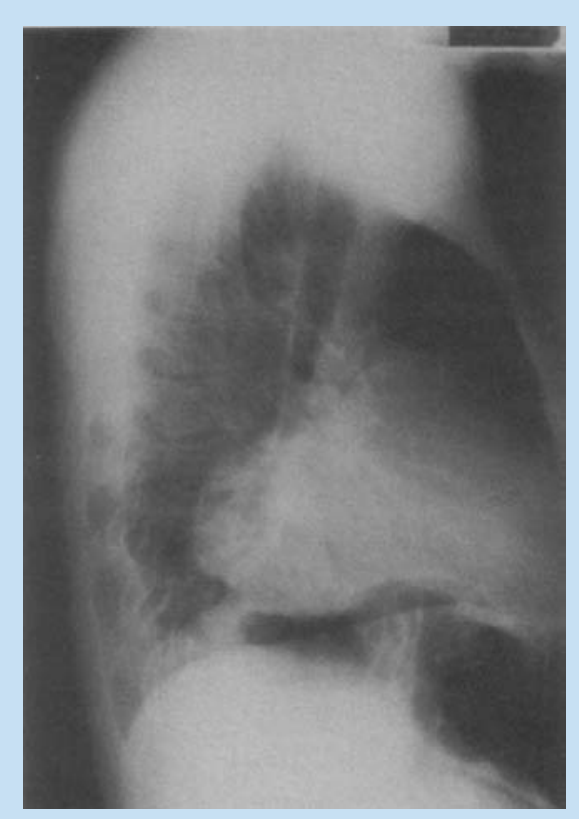

Fig. 10.

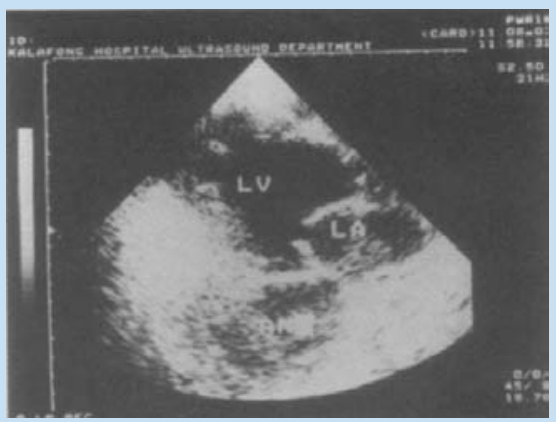

Fig. 11.

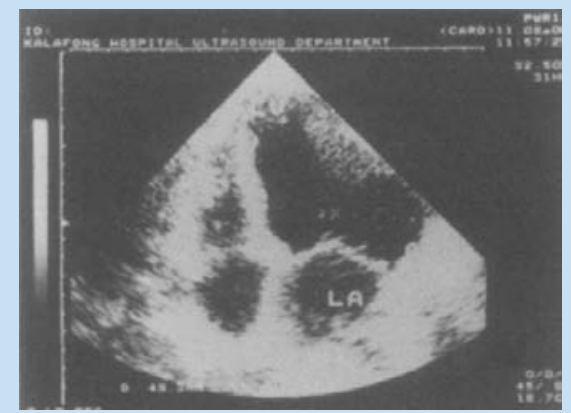

Fig. 12. 


\section{References}

1. Edelstein CL, Blake RS, Klopper JF. Mitral subannular left ventricular aneurysm. S Afr Med J 1987; 71: 114 - 115.

2. Chesler E, Joffe N, Schamroth C, Meyers A. Annular subvalvular left ventricular aneurysms in the South African Bantu. Circulation 1965; XXXII: 43 - 51.
3. Edington GM, Williams AO. Left atrial aneurysms associated with annular subvalvular left ventricular aneurysms. Journal of Pathology and Bacteriology 1968; 96: 273 -283.

4. Taneja K, Mathur A, Sharma S, Rajani M, Das B, Venugopal P. Magnetic resonance imaging features of submitral left ventricular aneurysm. Indian Heart J 1998; 50: 453 - 455.
5. Chesler E. Aneurysms of the left ventricle. Cardiovascular Clinics 1972; 4: 187 - 217.

6. Van de Werke I, Lockhat Z, Van der Walt E, Abdulla R. Calcified mitral subannular left ventricular aneurysm. South African Journal of Radiology 2000; 6: 33 - 35. 